\title{
FATORES DE RISCO PARA MENINGITE BACTERIANA NO RECÉM-NASCIDO
}

\author{
Vera Lúcia Jornada Krebs', Luciana Delboni Taricco²
}

\begin{abstract}
RESUMO - O objetivo do estudo é descrever os fatores de risco para meningite bacteriana em recém-nascidos e analisar a prevalência destes fatores, considerando-se a presença ou não de baixo peso ao nascimento. Foram analisados 50 recém-nascidos com meningite bacteriana, excluindo-se aqueles com meningomielocele ou infecção congênita. Na análise estatística utilizou-se o teste exato de Fisher, considerando-se significantes os valores de $p<0,05$. O estudo mostrou que a prematuridade, o baixo peso ao nascimento, e a presença de doenças infecciosas pré-existentes no recém-nascido ou na mãe estiveram fatores de risco importantes para meningite. Entre os recém-nascidos de baixo peso, os procedimentos invasivos, especialmente a intubação traqueal, o catéter venoso central e o uso prévio de antibióticos estiveram associados significativamente à ocorrência de meningite. Estes resultados indicam que a melhora na assistência pré-natal e no controle das infecções hospitalares constituem medidas de grande importância na diminuição da incidência de meningite bacteriana neonatal.
\end{abstract}

PALAVRAS-CHAVE: meningite, recém-nascido, fator de risco, infecção bacteriana.

\begin{abstract}
Risk factors for bacterial meningitis in the newborn
ABSTRACT - The aim of this study is to describe the risk factors for bacterial meningitis in newborns, and to analyze the prevalence of these factors, considering or not the low birth weight presence. Fifty newborns with bacterial meningitis were analyzed, excluding the ones with meningomyelocele or congenital infection. In the statistical analysis, the Fisher's exact test was used, considering significant the $p<0.05$ values. This study has shown that prematurity, low birth weight and presence of previous infectious diseases in the newborn or in the mother were important risk factors for meningitis. Among low birth weight newborns, invasive procedures, especially tracheal intubation, use of central venous catheter and previous use of antibiotics, were significantly associated to the meningitis occurrence. These results indicate that the improvement in the prenatal care and in the hospital infection control are measures of high importance in the decrease of the incidence of neonatal bacterial meningitis.
\end{abstract}

KEY WORDS: meningitis, newborn, risk factor, bacterial infection.

A meningite bacteriana é mais comum no primeiro mês de vida do que em qualquer outra faixa etária, com incidência variável de 0,22 a 2,66/1000 nascidos vivos nos diferentes países, tendendo a ser mais freqüente nas regiões menos desenvolvidas ${ }^{1-3}$. Apesar do advento de novos medicamentos e métodos diagnósticos sofisticados, a incidência de meningite bacteriana neonatal se alterou muito pouco nos últimos 30 anos. Este comportamento pode ser atribuído, em parte, ao grande número de recémnascidos pré-termo acometidos, ao tempo transcorrido entre o início da doença e a introdução do tratamento, ao tipo de bactéria, à sensibilidade do microorganismo aos antimicrobianos e à capacidade do antibiótico atingir o sítio de infecção ${ }^{4-6}$.
A mortalidade nos diferentes centros de tratamento varia de $17 \%$ a $29 \%$, com taxa de seqüelas de $15 \%$ a $68 \%$ dos sobreviventes ${ }^{3,7-10}$. Entre os fatores que influenciam o prognóstico da doença estão a prematuridade, o peso de nascimento, o tipo de bactéria, a sensibilidade do germe ao antimicrobiano, a duração do tratamento e a presença de complicações. Sabe-se que a doença é particularmente grave entre recém-nascidos pré-termo e de baixo peso, cujas taxas de mortalidade e seqüelas são mais altas em relação aos recém-nascidos de termo. Embora o diagnóstico precoce seja um dos recursos mais importantes para melhorar o prognóstico, a meningite neonatal caracteriza-se pela pobreza de sinais e sintomas na fase inicial do pro-

Instituto da Criança, Hospital das Clínicas (HC) da Faculdade de Medicina da Universidade de São Paulo (FMUSP), São Paulo SP, Brasil: ${ }^{1}$ Livre Docente em Pediatria pela FMUSP, encarregada de Setor Técnico da Unidade de Cuidados Intensivos Neonatal do Instituto da Criança do HC-FMUSP; ${ }^{2}$ Aluna do quinto ano da graduação da FMUSP, Bolsista de Iniciação Científica do CNPq. Estudo realizado com apoio do Conselho Nacional de Desenvolvimento Científico e Tecnológico (CNPq).

Recebido 29 Setembro 2003, recebido na forma final 5 Fevereiro 2004. Aceito 17 Março 2004.

Dra. Vera Lúcia Jornada Krebs - Rua Cristiano Viana 450/122 -05411-000 São Paulo SP - Brasil. E-mail: verakrebs@uol.com.br 
cesso infeccioso, tornando difícil sua detecção precoce. Os achados clínicos freqüentemente são inespecíficos e os sintomas neurológicos costumam surgir somente quando a infecção já se encontra em estágio avançado. Por estas razões, o conhecimento dos fatores de risco é fundamental, tanto para a prevenção como para o diagnóstico precoce da doença nesta faixa etária.

O presente estudo tem por objetivo descrever os fatores de risco para meningite bacteriana em recém-nascidos admitidos em Unidade de Terapia Intensiva e analisar a prevalência dos fatores de risco, considerando-se a presença ou não de baixo peso ao nascimento.

\section{MÉTODO}

Foi realizado um estudo observacional em 50 recémnascidos com meningite bacteriana internados na Unidade de Cuidados Intensivos Neonatal do Instituto da Criança do Hospital das Clínicas da Faculdade de Medicina da Universidade de São Paulo (FMUSP), no período de 1 de janeiro de 1998 a 31 de dezembro de 2002. Foram incluídos todos os recém-nascidos com diagnóstico de meningite bacteriana admitidos na Unidade durante este período, excluindo-se aqueles com meningomielocele ou infecções congênitas do sistema nervoso central. Os dados foram obtidos através da análise retrospectiva de prontuários, sendo preenchido um protocolo informando a idade, sexo, peso de nascimento, idade gestacional, antecedentes maternos e perinatais, fatores de risco e achados clínicos. O diagnóstico de meningite bacteriana foi estabelecido de acordo com o resultado do exame quimiocitológico do líquido cefalorraqueano (LCR), na presença de células $>20$ leucócitos $/ \mathrm{mm}^{3}$; predomínio de neutrófilos; proteinorraquia $>200 \mathrm{mg} / \mathrm{dl}$; glicorraquia $<50-75 \%$ da glicemia concomitante e/ou identificação de bactéria no exame bacterioscópico ou na cultura do $\mathrm{LCR}^{6,11,12}$.

Para analisar a possível associação entre o baixo peso ao nascimento e a prevalência de meningite bacteriana foi utilizado o teste exato de Fisher, considerando-se estatisticamente significantes os valores de p inferiores a 0,05.

O estudo foi aprovado pela Comissão de Pesquisa e Ética do Departamento de Pediatria da FMUSP, em 1 de julho de 2002 e pela Comissão de Ética para Análise de Projetos de Pesquisa do Hospital das Clínicas da FMUSP em 14 de agosto de 2002.

\section{RESULTADOS}

No período de 1 de janeiro de 1998 a 31 de dezembro de 2002 foram admitidos 1579 neonatos na Unidade de Cuidados Intensivos Neonatal do Instituto da Criança do HC/FMUSP, sendo $60 \mathrm{com}$ diagnóstico de meningite bacteriana. Foram excluídos 4 pacientes que apresentavam meningomie- locele e 6 com idade superior a 28 dias. Cinqüenta neonatos, que preencheram os critérios de inclusão, constituíram a casuística analisada (Tabela 1).

Dezenove pacientes (38\%) estavam recebendo tratamento com antibióticos antes do diagnóstico de meningite, devido à presença de infecção prévia. Houve 7 (14\%) óbitos, sendo 5 entre os recém-nascidos de baixo peso.

A idade materna variou de 15 a 40 anos, havendo 4 mães com idade inferior a 19 anos e 5 com idade superior a 34 anos.

Houve identificação de bactéria em 25 (50\%) recém-nascidos. As culturas de sangue e/ou LCR foram positivas em 23 (46\%), identificando-se Escherichia coli, Pseudomonas aeruginosa, Klebsiella pneumoniae, Acinetobacter baumanii, Alcalygenes xilosoxidans, Staphylococcus aureus, Staphylococcus epidermidis, Streptococcus viridans, Streptococcus mitis, Flavobacterium indologenes e Neisseria meningitidis. Em dois recém-nascidos (4\%) foi identificada Klebsiella sp e Staphylococcus aureus nas culturas de urina e líquido sinovial, respectivamente.

Quarenta e nove (98\%) recém-nascidos apresentavam um ou mais fatores de risco para meningite (Tabelas 2 e 3). O número de fatores de risco variou de 1 a 8 nos recém-nascidos com peso de nascimento $\geq 2500 \mathrm{~g}$ e de 3 a 11 entre os recém-nascidos de baixo peso.

Vinte e dois neonatos (44\%) apresentavam patologias infecciosas antes do diagnóstico de meningite e o tratamento com antibióticos havia sido instituído em 19 pacientes (38\%). As patologias préexistentes identificadas foram impetigo (8\%), infecção do sistema urinário (8\%), pneumonia (6\%), osteomielite $(4 \%)$, pioartrite $(4 \%)$, infecção de vias

Tabela 1. Descritores demográficos em 50 recém-nascidos com meningite bacteriana.

\begin{tabular}{lc}
\hline Descritores & Valores \\
\hline Idade à internação (dias) & $13,62(0,04-28,0) *$ \\
Peso ao nascer(g) & $2577,4(850-4810) *$ \\
Peso $\geq 2500 \mathrm{~g}$ & $27(54 \%)$ \\
Peso $<2500 \mathrm{~g}$ & $23(46 \%)$ \\
Idade gestacional (semanas) & $36,04(27-40,37) *$ \\
Pré-termo & $23(46 \%)$ \\
Termo & $27(54 \%)$ \\
Sexo masculino & $24(48 \%)$ \\
Sexo feminino & $26(52 \%)$ \\
Idade materna (anos) & $26,5(15-40) *$ \\
\hline *Valor médio (mínimo-máximo)
\end{tabular}


Tabela 2. Fatores de risco neonatais em 50 recém-nascidos com meningite bacteriana.

\begin{tabular}{lll}
\hline Fator de risco & $\mathrm{n}$ & $\%$ \\
\hline Prematuridade & 23 & 46 \\
Baixo peso ao nascer & 23 & 46 \\
Infecção prévia & 22 & 44 \\
Tratamento prévio com antibióticos & 19 & 38 \\
Ausência de aleitamento materno & 13 & 26 \\
Intubação traqueal & 12 & 24 \\
Asfixia perinatal & 9 & 18 \\
Catéter venoso central & 5 & 10 \\
Punção articular & 4 & 8 \\
Malformação cardíaca, urinária, digestiva & 3 & 6 \\
Drenagem de tórax & 2 & 4 \\
Procedimentos cirúrgicos & 1 & 2 \\
Gemelaridade & 1 & 2 \\
\hline
\end{tabular}

aéreas superiores $(4 \%)$, enterocolite necrosante $(4 \%)$, celulite de parede abdominal $(2 \%)$, abscesso cutâneo $(2 \%)$ e onfalite $(2 \%)$.

\section{DISCUSSÃO}

Observamos a presença de pelo menos um fator de risco em $98 \%$ dos recém-nascidos, principalmente prematuridade, baixo peso ao nascimento e presença de infecção prévia no recém-nascido ou na mãe. Estes resultados estão de acordo com outros estudos, que demonstraram ser a incidência de sepse e meningite inversamente proporcional à idade gestacional e ao peso de nascimento ${ }^{13,14}$. O baixo peso ao nascimento é um dos principais fatores associados à morbimortalidade perinatal. Freqüentemente estes neonatos são pré-termo, apresentam retardo de crescimento intra-uterino e necessitam de medidas de suporte para sua sobrevivência. Nestes recém-nascidos, a freqüência de meningite pode ser três vezes maior do que aquela observada nos recém-nascidos com peso igual ou superior a $2500 \mathrm{~g}^{6}$. Além disso, considerando-se separadamente o grupo de recém-nascidos de muito baixo peso ao nascimento $(<1500 \mathrm{~g})$, observamos que o risco de meningite é particularmente elevado nestes neonatos. Benedict et al. ${ }^{15}$ analisaram a evolução clínica de 39 recém-nascidos com peso de nascimento inferior a $1500 \mathrm{~g}$, portadores de meningite bacteriana ou fúngica, comparando-os com 25 recém-nascidos de muito baixo
Tabela 3. Fatores de risco maternos em 50 recém-nascidos com meningite bacteriana.

\begin{tabular}{lll}
\hline Fator de risco & $\mathrm{n}$ & $\%$ \\
\hline Infecção materna* & 19 & 38 \\
Diabetes mellitus & 5 & 10 \\
Hipertensão arterial & 5 & 10 \\
Idade > 34 anos & 5 & 10 \\
Idade < 19 anos & 4 & 8 \\
Eclâmpsia & 4 & 8 \\
Sangramento & 3 & 6 \\
Alcoolismo & 2 & 4 \\
Psoríase & 2 & 4 \\
Trabalho de parto prematuro & 2 & 4 \\
Uso de corticóide & 1 & 2 \\
Hipertireoidismo & 1 & 2 \\
\hline *Infecção urinária, vulvovaginite, fisometria, febre intraparto, toxo- \\
plasmose, bolsa rota >18h.
\end{tabular}

peso sem meningite. Os autores observaram que o peso e a idade gestacional foram significativamente mais baixos nos recém-nascidos que apresentaram meningite, em relação ao grupo controle.

A importância da prematuridade como fator de risco para meningite neonatal tem sido relatada por outros autores ${ }^{2,13,14}$ que destacam a condição de imaturidade do sistema imunológico destes neonatos. Embora os avanços na área de terapia intensiva neonatal tenham possibilitado a sobrevida de recém-nascido com prematuridade extrema, estes freqüentemente necessitam permanecer internados em Unidade de Terapia Intensiva por tempo prolongado, com maior tempo de exposição a microorganismos responsáveis pela ocorrência de infecção hospitalar. Além disso, os procedimentos invasivos, freqüentemente necessários para a sobrevida dos recém-nascidos pré-termo e de baixo peso, expõem os mesmos à colonização e infecção por patógenos que podem causar sepse e meningite. Entre os microorganismos isolados nas culturas dos neonatos de nossa casuística observamos a presença de bactérias sugestivas de contaminação hospitalar, como Pseudomonas aeruginosa, Klebsiella pneumoniae, Flavobacterium indologenes $^{12}$ Acinetobacter baumanii, Alcalygenes xilosoxidans e Staphylococcus epidermidis ${ }^{16,17}$.

A prematuridade e o baixo peso ocorrem freqüentemente associados a outros fatores agravantes, como infecção, materna durante o parto, 
especialmente nos casos de meningite de início precoce, nos primeiros quatro dias de vida. Os recémnascidos de mães que apresentam infecção do útero e do sistema urinário, são particularmente suscetíveis ${ }^{18}$ e a bactéria isolada no sítio de infecção materna poderá ser identificada na cultura de LCR do recém-nascido. Overall ${ }^{6}$ demonstrou que a presença de infecção materna e corioamnionite foi seis vezes mais freqüente em 25 neonatos com meningite, quando comparados a 46 recém-nascidos sem a doença. Em nossa casuística, 38\% das mães apresentavam doença infecciosa no final da gestação ou no momento do parto, ou rotura precoce da bolsa amniótica. Esta freqüência é superior à apresentada por Moura-Ribeiro, em nosso meio. Em 30 neonatos com meningite, a autora detectou contaminação e infecção com germes do aparelho genito-urinário materno em $30 \%$ dos $\operatorname{casos}^{19}$. O resultado obtido por nós é semelhante ao de Cervantes-Pardo et al. ${ }^{20}$, que observaram associação de meningite bacteriana com rotura prolongada das membranas amnióticas, parto com período expulsivo prolongado e vaginite materna em $38,5 \%$ de 26 neonatos.

Analisando a prevalência de fatores de risco em relação ao peso de nascimento, observamos que, além da prematuridade, a intubação traqueal, o catéter venoso central e o uso prévio de antibióticos foram significativamente mais freqüentes no grupo de recém-nascidos de baixo peso (Tabela 4). Dentre os procedimentos invasivos, a intubação traqueal foi o que mostrou maior associação com a ocorrência de meningite nos recém-nascidos de baixo peso $(p<0,0005)$. Devido à imaturidade pulmonar e/ou asfixia perinatal, a intubação traqueal é freqüente nestes neonatos. A bacteremia pode acompanhar procedimentos que traumatizem a mucosa do aparelho respiratório, como a inserção da cânula traqueal. Além disso, a aspiração traqueal nos recém-nascidos intubados favorece a infecção por microorganismos oportunistas ${ }^{2}$. Devem também ser considerados a contaminação da solução salina utilizada para umidificação da mucosa antes da sucção, dos nebulizadores que geram aerossóis ultra-sônicos e a diminuição dos mecanismos de defesa do epitélio ciliado, causada pela exposição prolongada do trato respiratório a altas concentrações de $\mathrm{O}_{2}{ }^{21}$. A presença de catéter vascular constitui importante porta de entrada para microorganismos na circulação sanguínea. A colonização do catéter venoso central favorece a ocorrência de bacteremia, sepse e meningite, causadas freqüentemente por cepas bacterianas hospitalares ${ }^{22}$.

Os focos infecciosos localizados em outros órgãos e o uso prévio de antibióticos são fatores de grande importância na patogênese do comprometimento do sistema nervoso central. Em 116

\begin{tabular}{|c|c|c|c|}
\hline \multirow[t]{3}{*}{ Fator de risco } & \multicolumn{2}{|c|}{ Peso de nascimento $(\mathrm{g})$} & \multirow[t]{3}{*}{$\mathrm{P}$} \\
\hline & $<2500(n=23)$ & $\geq 2500(n=27)$ & \\
\hline & $\mathrm{n}(\%)$ & n (\%) & \\
\hline Infecção materna & $10(43,5)$ & $9(33,3)$ & NS \\
\hline Sexo masculino & $10(43,5)$ & $14(51,8)$ & NS \\
\hline Infecção neonatal prévia & $11(47,9)$ & $11(40,7)$ & NS \\
\hline Prematuridade & $21(91,3)$ & $2(7,4)$ & 0,0001 \\
\hline Uso prévio de antibióticos & $13(56,5)$ & $6(22,2)$ & 0,0195 \\
\hline Intubação traqueal & $11(47,9)$ & $1(3,7)$ & 0,0005 \\
\hline Cateter venoso central & $5(21,7)$ & $0(0)$ & 0,0159 \\
\hline Ausência de aleitamento materno & $7(30,4)$ & $6(26,1)$ & NS \\
\hline Asfixia perinatal & $7(30,4)$ & $2(7,4)$ & NS \\
\hline Malformações (cardíaca, urinária, digestiva) & $3(13,0)$ & $1(3,7)$ & NS \\
\hline Idade materna $>34$ anos ou $<19$ anos & $3(13,0)$ & $6(22,2)$ & NS \\
\hline Punção (articular, abscesso), dreno torácico & $4(17,4)$ & $2(7,4 \%)$ & NS \\
\hline
\end{tabular}


lactentes com meningite piogênica, Lucena et al..$^{23}$ relataram a presença de infecção respiratória, otite ou infecção cutânea em $61,2 \%$ das crianças, tendo $22,8 \%$ recebido antibióticos antes do diagnóstico de meningite ${ }^{23}$. Em crianças maiores, a infecção respiratória alta ou a presença de otite constituem fatores de risco para infecção meníngea, devido à proximidade do foco infeccioso com o sistema nervoso central. Em neonatos, cuja principal via de infecção das meninges é hematogênica, qualquer foco infeccioso em outro órgão representa risco de disseminação. Nossos resultados indicam que esta forma de contaminação deve ter desempenhado um papel relevante na patogênese da infecção meníngea, pois $44 \%$ dos neonatos apresentavam infecção de pele, umbigo, pulmões, sistema urinário ou sistema ósteo-articular, antes do diagnóstico de meningite. A maioria destes pacientes recebeu tratamento com antibióticos, especialmente os recém-nascidos de baixo peso $(p=0,0195)$. Sabe-se que o uso de antibióticos de amplo espectro está relacionado à supressão da flora bacteriana normal, favorecendo o desenvolvimento de bactérias patogênicas. Outra conseqüência importante da antibioticoterapia é o incremento da resistência bacteriana e a emergência de cepas altamente virulentas, que respondem pouco aos medicamentos rotineiramente utilizados na Unidade de Terapia Intensiva.

Na maioria dos estudos sobre sepse neonatal, observa-se predomínio do sexo masculino. A razão da maior susceptibilidade dos meninos à doença ainda não está esclarecida. Sabe-se que a meningite bacteriana ocorre em cerca de $20 \%$ a $30 \%$ dos neonatos com sepse e alguns autores também relatam predomínio do sexo masculino na meningite bacteriana no período neonatal ${ }^{3}$. Este comportamento, porém, pode estar ausente ${ }^{8}$, não tendo sido observado em nossa casuística, que mostrou incidência semelhante em ambos os sexos.

Nosso estudo mostrou que a prematuridade, o baixo peso ao nascimento e a presença de doenças infecciosas pré-existentes no recém-nascido ou na mãe foram fatores de risco importantes para meningite. Entre os recém-nascidos de baixo peso, os procedimentos invasivos, especialmente a intubação traqueal, o uso de catéter venoso central e o uso prévio de antibióticos, foram associados significativamente à ocorrência de meningite durante a internação. Estes resultados indicam que a melhora na assistência pré-natal e no controle das infecções hospitalares constituem medidas de grande importância na diminuição da incidência de meningite bacteriana neonatal.

Agradecimento - Nosso agradecimento ao Dr. Ulysses Dória-Filho, pelas sugestões apresentadas.

\section{REFERÊNCIAS}

1. Harvey D, Holt DE, Bedford H. Bacterial meningitis in the newborn a prospective study of mortality and morbidity. Semin Perinatol 1999:23:18-25

2. Klein JO. Bacterial sepsis and meningitis. In Remington JS, Klein JO. (EDS) Infectious diseases of the fetus and newborn infant, $5^{\text {th. }}$ ed. Philadelphia: Saunders, 2000:943-998.

3. Moreno MT, Vargas S, Poveda R, Sáez-Llorens X. Neonatal sepsis and meningitis in a developing Latin American country. Pediatr Infect Dis J 1994;13:516-520.

4. Feigin RD. Bacterial meningitis in the newborn infant. Clin Perinatol 1977;4:103-116.

5. Nel E. Neonatal meningitis: mortality, cerebrospinal fluid, and microbiological findings. J Trop Pediatr 2000;46:237-239.

6. Overall JC. Neonatal bacterial meningitis: analysis of predisposing factors and outcome compared with matched control subjects. J Pediatr 1970;76:499-511.

7. Stevens JP, Eames M, Kent A, Halket S, Holt d, Harvey D. Long-term outcome of neonatal meningitis. Am Dis Child Fetal Neonatal 2003;88:179-184

8. Klinger G, Chin CN, Beyene J, Perlman M. Predicting the outcome of neonatal bacterial meningitis. Pediatrics 2000;106:477-482.

9. Krebs VLJ, Diniz EMA, Ceccon MEJ, Mangini NN, Ramos JLA, Vaz FAC Secuelas auditivas de la meningitis bacteriana neonatal: estudo de 32 recién-nascidos. Bol Med Hosp Inf Mex 1997;54:369-374.

10. Krebs VLJ, Diniz EMA, Vaz FAC, Marques-Dias MJ, Takiguti C, Ramos JLA. Meningite bacteriana neonatal: estudo prospectivo da evolução a longo prazo de 55 crianças. Arq Neuropsiquiatr 1996;54:75-81.

11. Feferbaum R, Vaz FAC, Krebs VLJ, Diniz EMA, Ramos SRT, Manissadjian A. Meningite bacteriana no período neonatal: evolução clínica e complicações em 109 casos. Arq Neuropsiquiatr 1996;51:72-79.

12. Ramos SRT, Feferbaum R, Manissadjian A, Vaz FAC. Meningite bacteriana neonatal: agentes etiológicos em 109 casos durante período de dez anos. Arq Neuropsiquiatr 1992;50:289:294.

13. Zaki M, Daoud AS, AL Saleh Q, Al Rassol MM. Bacterial meningitis in the newborn: a Kuwait experience. J Trop Pediatr 1990;36:63-65.

14. Persson E, Trollfors B, Brandberg LL, Tessin I. Septicaemia and meningitis in neonates and during early infany in the Göteborg area of Sweden. Acta Paediatr 2002;91:1087-1092.

15. Benedict A, Newman N, Minich MN, Taylor HG, Fanaroff AA, Hack $\mathrm{M}$. Clinical outcomes of neonatal meningitis in very-low-birth-weight infants. Clin Pediatr 2001;40:473-480.

16. Drinkovic D, Pottumarthy S, Knight D, Morris AJ. Neonatal coagulasenegative staphylococcal meningitis: a report of two cases. Pathology 2002;34:586-588

17. Heath TP, Yosoff NKN, Baker JC. Neonatal meningitis. Arch Dis Child Fetal Neonatal 2003;88:173-178.

18. Berman $\mathrm{PH}$, Banker $\mathrm{BQ}$. Neonatal meningitis: a clinical an pathological study of 29 cases. Pediatrics 1966;38:6-24

19. Moura-Ribeiro MVL. Meningites purulentas em crianças no primeiro ano de vida. Arq Neuropsiquiatr 1990;48:161-168.

20. Cervantes-Pardo A, Tauler GMC, et al. Meningitis neonatal: estudio de 28 casos y revision de sus secuelas a los cinco anos. An Esp Pediatr 1988;28:503-507.

21. Storm W. Transient bacteremia following endotracheal suctioning in ventilated newborns. Pediatrics 1980;65:487-490.

22. Gaynes RP, Edwards JR, Jarvis WR, Culver DH, Tolson JS, Martone WJ Nosocomial infections among neonates in high-risk nurseries in United States. Pediatrics 1996;98:357-361.

23. Lucena R, Gomes I, Cardoso E, et al. Aspectos clínicos e laboratoriais de meningite piogênica em lactentes. Arq Neuropsiquiat 2002;60:281284 